Please do not remove this page

RMIT

UNIVERSITY

\title{
Techniques used by investigative interviewers to elicit disclosures of abuse from child witness: a critique
}

Hughes-Scholes, Carolyn; Powell, Martine

https://researchrepository.rmit.edu.au/esploro/outputs/9921859040401341/filesAndLinks?institution=61RMIT_INST\&index=null

Hughes-Scholes, C., \& Powell, M. (2012). Techniques used by investigative interviewers to elicit disclosures of abuse from child witness: a critique. Police Practice and Research, 14(1), 45-52.

https://doi.org/10.1080/15614263.2012.680716

Document Version: Accepted Manuscript

Published Version: https://doi.org/10.1080/15614263.2012.680716

Repository homepage: https://researchrepository.rmit.edu.au

(C) Taylor \& Francis

Downloaded On 2023/04/26 23:06:40 +1000

Please do not remove this page 


\section{DMIT \\ UNIVERSITY}

Thank you for downloading this document from the RMIT Research Repository.

The RMIT Research Repository is an open access database showcasing the research outputs of RMIT University researchers.

RMIT Research Repository: http://researchbank.rmit.edu.au/

\section{Citation:}

Hughes-Scholes, C and Powell, M 2012, 'Techniques used by investigative interviewers to elicit disclosures of abuse from child witness: a critique', Police Practice and Research, pp. 1-8.

See this record in the RMIT Research Repository at:

http://researchbank.rmit.edu.au/view/rmit:17546

Version: Accepted Manuscript

Copyright Statement: (c) Taylor \& Francis

Link to Published Version:

http://dx.doi.org/10.1080/15614263.2012.680716

PLEASE DO NOT REMOVE THIS PAGE 
Techniques used by investigative interviewers to elicit disclosures of abuse from child witnesses: A critique

Carolyn H. Hughes-Scholes and Martine B. Powell

Deakin University

Keywords: Investigative interviewing, Child sexual abuse, Interviewer training, Police, Witnesses, Disclosures.

Notes on Contributors

Carolyn Hughes-Scholes is a Research Fellow in the School of Psychology, Deakin University. Dr Hughes-Scholes has been a researcher in the area of children's eyewitness testimony and police interviewing for the past 12 years.

Martine Powell is Professor of Psychology, Deakin University. For the past 18 years, she has conducted research on child eyewitness memory and investigative interviewing and has played a major role in the design and implementation of interviewer training programs throughout Australia. 


\begin{abstract}
Eliciting disclosures of abuse from children is a challenging skill that requires considerable practice, feedback, training, and instruction. While there is an abundance of literature outlining what constitutes best practice interviewing of children, there has been little discussion, in particular, of investigative interviewers' limitations when applying bestpractice interview guidelines to elicit disclosures of abusive acts. This paper assists police by identifying common problems of child investigative interviewers when eliciting disclosures $(N=131)$ and provides alternate questioning strategies. The results support the need for further training to be developed to ensure better adherence to best-practice guidelines in relation to all aspects of eliciting a disclosure from children.
\end{abstract}




\section{Techniques used by investigative interviewers to elicit disclosures of abuse}

\section{from child witnesses: A critique}

The task of eliciting statements of abuse from child witnesses can be very challenging. Researchers across Europe, the US, and Australasia have highlighted this challenge by documenting the use of leading and other inappropriate questions in their evaluations of interviews, and by showing that the rate of these questions is largely resistant to change preand post-training unless the training involves considerable ongoing practice and expert feedback (Powell, Fisher, \& Wright, 2005). Providing interviewers with a general interview guide or framework that adheres to recommended practices does not assure that they are conducting interviews in a manner that maximises the quality of evidence. Interviewers must also have the tools (effective questions) to apply the framework. Such tools, and the capacity to use them, need to be learned because they are not normally used in English-speaking cultures (Powell, 2002).

The central premise of all interview protocols is that the child should be allowed to report what happened in his own words and the interviewer, where possible, should use nonleading open-ended questions: questions that encourage an elaborate response but do not dictate what specific information is required (Powell \& Snow, 2007b). It is recommended that specific questions (i.e., closed, or Who, What, When, Where questions) be avoided until after free narrative has been exhausted because the information provided in response to such questions is less likely to be accurate than information in response to open-ended questions (Dent \& Stephenson, 1979; Lamb \& Fauchier, 2001; Oates \& Shrimpton, 1991; Orbach \& Lamb, 2001). The problem is that open-ended questions are not always effective in eliciting details of abuse, particularly in the case of reluctant witnesses and those who are not clear about the purpose of the interview (Hershkowitz, et al. 2007; Orbach, et al., 2007). A child may be reluctant to disclose for a variety of cognitive, emotional, or motivational reasons, such as limited communication skills, embarrassment, a desire to protect the offender, fear of 
the consequences of reporting abuse, or lack of awareness that abuse has actually occurred (Powell \& Snow, 2007a). When children do not disclose in response to the initial non-leading open-ended prompts, there is a tendency for interviewers to use increasingly specific and suggestive prompts (Wright \& Powell, 2006).

Notwithstanding the fact that specific and leading questions may be necessary during interviews, research shows that these questions are often used by interviewers before they attempt to use open-ended questions that have a lower risk of eliciting error (Powell \& Hughes-Scholes, 2009). Further, not all open-ended questions are equally effective in eliciting disclosures of abuse; questions need to be matched to the child's developmental level, they need to avoid issues of potential contention (e.g., the alleged offender and the alleged act), and they ideally need to focus the child on what happened as opposed to eliciting descriptive information (Powell \& Guadagno, 2008). The current paper elaborates on these issues by documenting the types of questioning strategies used by interviewers in eliciting disclosures of abuse, and outlining alternate (more appropriate) questions that could have been asked in their place.

The current study provides a critique of interviewers' use of questions in eliciting disclosures of abuse. Several prior studies have conducted similar evaluations; however, these prior studies have tended to focus on the initial phase of the interview (when the interviewer attempts to establish the topic of concern) and have been fairly broad in their descriptions (i.e., noting whether or not the interviewer adhered to non-leading open-ended questions). For example, Sternberg et al., (2001) examined interviews conducted by investigative interviewers who were trained in a highly structured narrative-based interview (National Institute of Child Health and Human Development protocol). They found that in accordance with best-practice guidelines, 98 percent of the interviewers began the substantive phase of the interview by asking the child a non-leading open-ended question to try to elicit a disclosure. Korkman et al. (2008) analysed interviews conducted by clinical mental health 
professionals who had received little to no training in forensic interviewing and who did not use structured interview protocols. Only 21 percent of the interviewers asked children to explain in their own words the purpose of the interview. Instead, interviewers were more likely to ask highly specific and sometimes even leading questions in an attempt to elicit a disclosure (e.g., references to something that someone else had claimed had happened to the child, references to something bad or negative having happened to the child) (p. 49). Similarly, Warren, Woodall, Hunt, and Perry (1996), who analysed interviews conducted between 1988 and 1992 before best-practice interview guidelines had been established, found that less than half of the interviewers in their study (40\%) tried to elicit a disclosure using open-ended prompts. Instead, interviewers tended to raise prior information about the nature of the allegation (45\%) (e.g., "I heard that someone has touched or hurt you”) or made reference to a previous interview (14\%). This study extends the prior research by examining more closely the way in which the interviewer elicits disclosures of abuse throughout the entire interview and the way in which the questions could be improved. The value of providing such critiques of interviewer performance is that it may assist trainers in guiding the further development of trainee interviewers.

\section{Method}

\section{Summary of the Field Interviews}

The sample of interviews included 131 videotaped child witness statements, conducted by 92 (71 female, 21 male) police officers from child abuse investigation units situated in two police organisations across Australia. The interviews were conducted between 2001 and 2007. The procedure of recruiting these interviews initially involved a member of the police organisation selecting witness statements from storage. Interviews were selected randomly with the constraint that there was a range across years and that they constituted the first electronically recorded interview with the child about the alleged offense. Identification codes regarding these interviews were then sent to the officers who originally conducted the interviews along with instructions 
requiring them to seek formal consent from the caregivers for the interview to be included in the research. Overall, data collection (using the above-mentioned procedure) was continued until a relatively large number $(N=131)$ of interviews were obtained. All interviews were transcribed and the transcripts were de-identified prior to submission.

The witnesses in these interviews were children (46 males, 85 females) aged 3 to 15 years ( $M$ age $=9$ years 8 months; $S D=2$ years 9 months). The children reported a variety of sexual and physical abuse experiences. These included offering financial inducement for a sexual act $(N=3)$, exposure $(N=7)$, touching over clothes $(N=26)$, touching under clothes ( $N=35)$, and penetration $(N=35)$. Physical abuse was reported by 23 children. In two interviews, the child witness did not disclose abuse. In 69 interviews, the child reported multiple incidents of abuse. The alleged perpetrator categories were immediate family members $(N=41)$, other relatives $(N=18)$, familiar but unrelated adults $(N=37)$, unfamiliar adults $(N=9)$, familiar children $(N=14)$, and unknown $(N=10)$ (that is, the child did not indicate who the alleged perpetrator was).

The sample of interviewers was heterogeneous, consisting of officers of various ranks (Constable to Detective) and from diverse areas, including metropolitan and rural areas. Note that all of the officers were authorised to conduct investigative interviewers with children and had completed specialised training in this area that: (a) was administered by experts: (b) had spanned several weeks: (c) included instruction in the definitions of various questions, a rationale for using open-ended questions, and exemplars of good interviewing practice: and, (d) incorporated multiple practice opportunities accompanied by critical feedback in appropriate interviewing techniques. On average, the officers had gained their qualification 3 years 9 months prior to the interview being conducted (range $=1$ day to 11 years).

\section{Coding}

The type of questioning strategy used to establish the initial topic of concern and/or the precise abusive act was noted, as well as the order in which various questions were asked 
when multiple attempts were made to elicit a disclosure of the precise abusive act. Interviewer questions were divided into the following categories:

(i) Open-ended questions referred to questions that were designed to elicit an account of the event in the child's own words, but did not dictate the information that the child needed to report (e.g., "You mentioned that you tripped over. Tell me everything that happened.”).

(ii) Specific questions referred to questions that focused the child on specific aspects of the abuse (e.g., "You said Mr. Smith took your clothes off. What clothes were you wearing?”)

(iii) Suggestive questions were those questions that presumed at least one specific detail that had not previously been mentioned by the child (e.g., "Tell me about the stick your mum hit you with” when the child had not previously mentioned that her mother hit her with a stick).

All interviewers' questions contained within the transcripts were coded by one researcher and 20 percent of these were also coded by a second researcher who was not otherwise involved in the study. Inter-rater reliability, calculated as agreements/ (agreements + disagreements), was at least $90 \%$ for each of the categories listed above.

\section{Results and Discussion}

\section{Method of Eliciting an Initial Disclosure}

First attempt to elicit an initial disclosure. Five of the 131 children spontaneously disclosed abuse at the outset of the interview. Therefore, these interviews are excluded from the rest of the analyses. Of the remaining 126 interviews, 120 (95.2\%) of the interviewers began by asking what the purpose of the interview was (e.g., "Tell me what you've come here to talk to me about today”). This technique is consistent with best-practice guidelines except that almost half the questions (45.2\%) were phrased in a closed manner (e.g., "Can you tell me/Do you know what you've come here to talk to me about today?”) which is not 
ideal because children have the tendency to respond with either 'yes' or 'no' to these questions (Powell, 2003; Powell \& Snow, 2007a). Indeed, questions phrased in a closed manner were less successful in eliciting a disclosure from a child (66.7\% disclosure rate) than when phrased in an open manner (90.5\% disclosure rate), $\chi^{2}(1)=10.69, p<.001$.

Four of the remaining six interviewers raised leading information which referred to a prior interview or the alleged offender (e.g., "Before we started the camera, we spoke about something that happened between your mum and dad on Friday”) without first seeking clarification from the child as to whether this information was correct. The problem with raising issues of contention such as the alleged offender's identity and presuming that the information is correct is that there is the danger that the child will provide a false account of abuse (Hughes-Scholes \& Powell, 2008). Finally, two interviewers asked about family members (i.e., good /bad things about various family members) to try to elicit an initial disclosure (e.g., "So what are some of the nice things you like about Mum?”, "Is there anything about Mum that you don’t like?”). This technique is not recommended because children may not associate abuse (if it occurred) with the term 'bad' (Powell, 2003). Further, this technique may elicit information from the child about non-abusive events that the interviewer misinterprets as abusive events (Poole \& Lamb, 1998).

Subsequent attempts to elicit an initial disclosure. For the 28 children who did not provide any abuse-related information (e.g., the identity of the offender, the nature of the abuse, or the time/location of the abuse) in response to the initial prompt, further attempts at eliciting a disclosure were made by the interviewers. Of the 52 subsequent attempts made to elicit a disclosure across 28 interviews, asking the purpose of the interview was the most common method (21/52, 40.4\%), followed by asking about secrets or family members (17/52, 32.7\%), and raising leading information (referring to a prior interview, when the abuse occurred, the nature of the act, and/or the identity of the offender) (14/52, 26.9\%). The 
following is an example of an interviewer's attempts to elicit an initial disclosure from a 5year-old girl using each of the above techniques:

Interviewer: Do you know why you're talking to me today?

Child: (no response)

Interviewer: Alright. Has anybody else ever lived at your house apart from Dan and Alex and your mum?

Child: $\quad$ No.

Interviewer: Alright. Have you talked to your mum recently about something that made you feel a bit yucky and uncomfortable?

Child: (nods)

Interviewer: What was that you talked to your mum about?

Child: $\quad$ About Bruce.

Interviewer: Bruce. Oh yeah. And what did you tell your mum about Bruce?

Child: $\quad$ He rubbed his rude bit on mine.

Child aged 5 years.

The interviewer in the above example starts by asking the purpose of the interview; and, when the child provides no response the interviewer 'fishes' for a disclosure by asking about who has lived at the child's house (excluding the family members mentioned during the rapport phase of the interview). When the child does not mention the name of the alleged offender, the interviewer raises the context of a prior disclosure to another adult (i.e., the child's mother) without mentioning the content of the disclosure. The interviewer may have elicited a disclosure earlier in the interview if (s)he had raised the prior information before ‘fishing' for a disclosure.

There was no pattern evident in terms of the order in which interviewers used the techniques to elicit a disclosure. For example, some interviewers used more specific techniques in subsequent attempts (asking the purpose of the interview followed by raising 
prior information), whereas other interviewers used the same techniques repeatedly (e.g., asking about family members).

Questions used once child had provided an initial disclosure. Of the 28 children who did not disclose any abuse-related information in response to the initial prompt, 26 children (92.9\%) disclosed in response to the interviewer's subsequent attempts to elicit a disclosure. However, two children never provided a disclosure during the interview. Once the child had provided an initial disclosure, $70.5 \%$ of the interviewers followed best-practice guidelines and asked an open-ended question (e.g., “Tell me everything that happened when your cousin tried to kiss you. Start from the beginning.”),or used a minimal encourager (e.g., mhmm, aha) to elicit a free-narrative account of what had happened to the child. The remaining $29.5 \%$ asked a specific question to request specific details about the event. These specific details usually focused on the alleged offender (e.g., "Who is Dave?”, "Where does he live?”), or contextual details surrounding the alleged abuse (e.g., "When did you go to your uncle’s house?”, “Who was there that day?”). Best-practice guidelines recommend asking open-ended questions once a child has disclosed because these types of questions elicit more accurate information than specific questions and allow the child to provide an account of what happened in his/her own words as opposed to dictating what specific information is required (Lamb, et al., 2007; Powell \& Snow, 2007b).

\section{Eliciting a Detailed Disclosure of the Abusive Act}

Next, we examined the techniques interviewers used to elicit a detailed disclosure of the precise abusive act that subsequently formed the charge (e.g., "Sam has been touching my breasts") in the event that the child had not provided this during the early stages of the interview (i.e., in response to the initial prompt or the initial open-ended question used to commence the narrative once the child had provided an initial disclosure). 
Of those 49 cases where the child did not provide a detailed disclosure of the abusive act initially, 34.7\% (17/49) of the interviewers asked the child a series of specific questions (usually about the alleged offender or contextual details surrounding the abusive act, such as temporal or location details) followed by open-ended questions in an attempt to elicit the abusive act. For example:

Interviewer: Can you tell me why you're here today?

Child: $\quad$ To talk about Adam and what he did.

Interviewer: Okay. And who's Adam?

Child: $\quad$ My step-dad's uncle.

Interviewer: And do you know his full name?

Child: $\quad$ No.

Interviewer: How long have you known him for?

Child: $\quad$ I don’t know.

Interviewer: So, you're here to talk about Adam and what he did. Tell me everything about that day.

Child: $\quad$ Well, it was the Christmas party at Adam's house, and we got in the car. We got everything ready and we drove to where they lived.

Interviewer: And then what happened?

Child aged 10 years 9 months.

The problem with the approach used in the above example is that the interviewer did not follow up the child’s initial disclosure (i.e., "To talk about Adam and what he did”), but, instead, asked questions regarding the offender that could have been left until later in the interview after free narrative had been exhausted. The interviewer should have asked an open-ended question such as “Tell me everything that happened with Adam” to elicit a disclosure in the child's own words (Powell \& Guadagno, 2008). 
Another technique used by five of the 49 (10.2\%) interviewers was to ask open-ended questions to elicit a free narrative of what had happened to the child, but then to interrupt the child and ask specific questions. Other interviewers (5/49, 10.2\%) asked predominantly openended questions but interspersed them with specific questions, or vice versa (4/49, 8.2\%). The remaining interviewers (18/49, 36.7\%) asked one type of question repeatedly in an attempt to elicit the abusive act. While 8 interviewers acted in accordance with best-practice guidelines and asked a series of open-ended questions, an additional 8 interviewers asked specific questions repeatedly and a further 2 asked suggestive questions repeatedly (e.g., “And what did he do when he touched you on the fanny?” when the child had not specifically mentioned being touched on the vagina previously). The latter technique is not advised as repeatedly suggesting information may lead a child to provide a false report of abuse (Bruck, Ceci, \& Hembrooke, 2002; Powell, Jones, \& Campbell, 2003).

All except three of the 49 children who did not provide a detailed disclosure of the abusive act initially eventually provided a detailed disclosure of the precise abusive act. Interestingly, when children provided a disclosure of the abusive act it was more likely to be in response to an open-ended question (28/46, 60.9\%) (in particular, an open-ended question that asked the child to elaborate on an aspect of the event that had been disclosed earlier) rather than a specific (16/46, 34.8\%) or suggestive (2/46, 4.4\%) question, $\chi^{2}(2)=22.09, p<$ .001. This finding highlights the importance of asking open-ended questions when attempting to elicit a disclosure of abuse from children.

\section{Concluding comment}

Overall, this study highlights the need for further training to ensure that interviewers adhere (where possible) to best-practice guidelines in interviews with child witnesses about abuse. There were two aspects of eliciting a disclosure that tended to cause interviewers to deviate from best-practice guidelines. The first aspect was when children did not disclose at all in response to the initial prompt. Here, the interviewers were likely to use problematic 
techniques including raising issues of contention, such as the alleged offender's identity, or asking questions about family members. The second aspect of eliciting a disclosure that interviewers found difficult was when children did not disclose the precise abusive act that subsequently formed the charge during the initial stages of the interview. Rather than asking open-ended questions to elicit a narrative account of what happened, the interviewers were inclined to ask specific (more risky) questions first.

The interviews analyses have resulted in a finding that further training needs to be developed to ensure better adherence to best-practice guidelines in relation to all aspects of eliciting a disclosure. This could involve trainers providing interviewers with concrete examples of questions to ask in situations where a child does not provide an initial disclosure in response to asking the purpose of the interview. The interviewers could then be invited to practice preparing such questions. In addition, trainers could observe interviewers practicing the use of open-ended questions to elicit a disclosure of the precise abusive act in the context of mock interviews and provide feedback where appropriate. Further training will enable interviewers to give children the assistance they need to provide a detailed and accurate disclosure of abuse. 
References

Bruck, M., Ceci, S. J., \& Hembrooke, H. (2002). The nature of children's true and false narratives. Developmental Review, 22, 520-554.

Dent, H. R., \& Stephenson, G. M. (1979). An experimental study of the effectiveness of different techniques of questioning child witnesses. British Journal of Social and Clinical Psychology, 18, 41-51.

Hershkowitz, I., Orbach, Y., Sternberg, J., Pipe, M-E., Lamb, M. E., \& Horowitz, D. (2007). Suspected victims of abuse who do not make allegations: An analysis of their interactions with forensic interviewers. In M-E. Pipe, M. E. Lamb, Y. Orbach, \& A. C. Cederborg (Eds.), Child sexual abuse: Disclosure, delay, and denial (pp. 97-114). Mahwah, NJ: Lawrence Erlbaum Associates Inc.

Hughes-Scholes, C. H., \& Powell, M. B. (2008). An examination of the types of leading questions used by investigative interviewers of children. Policing: An International Journal of Police Strategies and Management, 31, 210-225.

Korkman, J., Santtila, P., Drzewiecki, T., \& Sandnabba, N. K. (2008). Failing to keep it simple: Language use in child sexual abuse interviews with 3-8-year-old children. Psychology, Crime \& Law, 14, 41-60.

Lamb, M. E., \& Fauchier, A. (2001). The effects of question type on self-contradictions by children in the course of forensic interviews. Applied Cognitive Psychology, 15, 1-9.

Lamb, M. E., Orbach, Y., Hershkowitz, I., Esplin, P. W., \& Horowitz, D. (2007). A structured forensic interview protocol improves the quality and informativeness of investigative interviews with children: A review of research using the NICHD investigative protocol. Child Abuse \& Neglect, 31, 1201-1231.

Oates, K., \& Shrimpton, S. (1991). Children’s memories for stressful and non-stressful events. Medicine, Science, and the Law, 31, 4-10. 
Orbach, Y., \& Lamb, M. E. (2001). The relationship between within-interview contradictions and eliciting interviewer utterances. Child Abuse and Neglect, 25, 323-333.

Orbach, Y., Shiloach, H., \& Lamb, M. E. (2007). Reluctant disclosers of sexual abuse.

In M. E. Pipe, M. E. Lamb, Y. Orbach, \& A. C. Cederborg (Eds.), Child sexual abuse: Disclosure, delay, and denial (pp. 115-134). Mahwah, NJ: Lawrence Erlbaum Associates Inc.

Poole, D. A., \& Lamb, M. E. (1998). Investigative interviews of children: A guide for helping professionals. Washington, DC: American Psychological Association.

Powell, M. B. (2002). Specialist training in investigative and evidential interviewing: Is it having any effect on the behaviour of professionals in the field? Psychiatry, Psychology and Law, 9, 44-55.

Powell, M. B. (2003). A guide to introducing the topic of an interview about abuse with a child. Australian Police Journal, 57, 259-263.

Powell, M. B., Fisher, R. P., \& Wright, R. (2005). Investigative interviewing. In N. Brewer, \& K. Williams (Eds.), Psychology and law: An empirical perspective (pp. 11-42). New York: Guilford.

Powell, M. B., \& Guadagno, B. L. (2008). An examination of the limitations in investigative interviewers’ use of open-ended questions. Psychiatry, Psychology and Law, 15, 382-395.

Powell, M. B., \& Hughes-Scholes, C. H. (2009). An evaluation of the questions used to elicit evidence about abuse from child witnesses: An Australian study. Psychiatry, Psychology and Law, 16, 369-378.

Powell, M. B., Jones, C. H., \& Campbell, C. (2003). A comparison of preschooler's recall of experienced versus non-experienced events across multiple interviews. Applied Cognitive Psychology, 17, 935-952.

Powell, M. B., \& Snow, P. C. (2007a). Recommendations for eliciting a disclosure of abuse from a young child. Australian Police Journal, 61, 76-78. 
Powell, M. B., \& Snow, P. C. (2007b). Guide to questioning children during the free-narrative phase of an investigative interview. Australian Psychologist, 42, 57-65.

Sternberg, K. J., Lamb, M. E., Orbach, Y., Esplin, P. W., \& Mitchell, S. (2001). Use of a structured investigative protocol enhances young children's responses to free-recall prompts in the course of forensic interviews. Journal of Applied Psychology, 86, 9971005.

Warren, A. R., Woodall, C. E., Hunt, J. S., \& Perry, N. W. (1996). "It sounds good in theory, but ...”: Do investigative interviewers follow guidelines based on memory research? Child Maltreatment, 1, 231-245.

Wright, R., \& Powell, M. B. (2006). Investigative interviewers’ perceptions of their difficulty in adhering to open-ended questions with child witnesses. International Journal of Police Science and Management, 8, 316-325. 